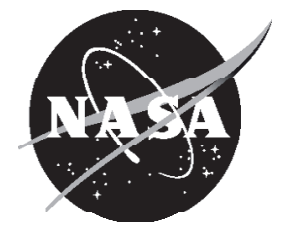

\title{
Environmental Testing of the NEXT PM1 Ion Engine
}

John S. Snyder and John R. Anderson

Jet Propulsion Laboratory, Pasadena, California

Jonathan L. Van Noord and George C. Soulas

Glenn Research Center, Cleveland, Ohio 


\section{NASA STI Program . . . in Profile}

Since its founding, NASA has been dedicated to the advancement of aeronautics and space science. The NASA Scientific and Technical Information (STI) program plays a key part in helping NASA maintain this important role.

The NASA STI Program operates under the auspices of the Agency Chief Information Officer. It collects, organizes, provides for archiving, and disseminates NASA's STI. The NASA STI program provides access to the NASA Aeronautics and Space Database and its public interface, the NASA Technical Reports Server, thus providing one of the largest collections of aeronautical and space science STI in the world. Results are published in both non-NASA channels and by NASA in the NASA STI Report Series, which includes the following report types:

- TECHNICAL PUBLICATION. Reports of completed research or a major significant phase of research that present the results of NASA programs and include extensive data or theoretical analysis. Includes compilations of significant scientific and technical data and information deemed to be of continuing reference value. NASA counterpart of peer-reviewed formal professional papers but has less stringent limitations on manuscript length and extent of graphic presentations.

- TECHNICAL MEMORANDUM. Scientific and technical findings that are preliminary or of specialized interest, e.g., quick release reports, working papers, and bibliographies that contain minimal annotation. Does not contain extensive analysis.

- CONTRACTOR REPORT. Scientific and technical findings by NASA-sponsored contractors and grantees.

- CONFERENCE PUBLICATION. Collected papers from scientific and technical conferences, symposia, seminars, or other meetings sponsored or cosponsored by NASA.

- SPECIAL PUBLICATION. Scientific, technical, or historical information from NASA programs, projects, and missions, often concerned with subjects having substantial public interest.

- TECHNICAL TRANSLATION. Englishlanguage translations of foreign scientific and technical material pertinent to NASA's mission.

Specialized services also include creating custom thesauri, building customized databases, organizing and publishing research results.

For more information about the NASA STI program, see the following:

- Access the NASA STI program home page at http://www.sti.nasa.gov

- E-mail your question via the Internet to help@ sti.nasa.gov

- Fax your question to the NASA STI Help Desk at 301-621-0134

- Telephone the NASA STI Help Desk at 301-621-0390

- Write to: NASA Center for AeroSpace Information (CASI) 7115 Standard Drive Hanover, MD 21076-1320 


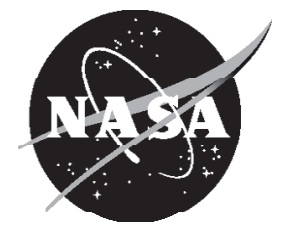

\section{Environmental Testing of the NEXT PM1 Ion Engine}

John S. Snyder and John R. Anderson

Jet Propulsion Laboratory, Pasadena, California

Jonathan L. Van Noord and George C. Soulas

Glenn Research Center, Cleveland, Ohio

Prepared for the

43rd Joint Propulsion Conference

sponsored by the American Institute of Aeronautics and Astronautics

Cincinnati, Ohio, July 8-11, 2007

National Aeronautics and

Space Administration

Glenn Research Center

Cleveland, Ohio 44135 


\section{Acknowledgments}

The work described in this paper was carried out by the Jet Propulsion Laboratory (JPL), California Institute of Technology, under a contract with the National Aeronautics and Space Administration. The PM1 Environmental Test program, funded by NASA's In-Space Propulsion Technology Program, was successfully accomplished through the efforts of a multiorganizational team. The work was performed under the NEXT Project, led by the NASA Glenn Research Center (GRC), with Scott Benson as the Project Manager and Mike Patterson as the Principal Investigator. Kevin McCormick, Daniel Herman, and George Williams of GRC spent a significant amount of time at JPL during the testing described herein and were instrumental in performing this work. Andy Hoskins of Aerojet also provided support for the test. At JPL, Allison Owens and Ray Swindlehurst were responsible for designing, configuring, and operating the test facility. Rich Ebner, Tim Werner, and Doug Perry of the JPL Environmental Test Lab were responsible for setup, instrumentation, and performing the vibration test. Their efforts and contributions are greatly appreciated.

This report is a formal draft or working paper, intended to solicit comments and ideas from a technical peer group.

Trade names and trademarks are used in this report for identification only. Their usage does not constitute an official endorsement, either expressed or implied, by the National Aeronautics and Space Administration.

Level of Review: This material has been technically reviewed by technical management.

Available from

NASA Center for Aerospace Information 7115 Standard Drive Hanover, MD 21076-1320
National Technical Information Service 5285 Port Royal Road Springfield, VA 22161 


\title{
Environmental Testing of the NEXT PM1 Ion Engine
}

\author{
John S. Snyder and John R. Anderson \\ Jet Propulsion Laboratory \\ Pasadena, California 91109 \\ Jonathan L. Van Noord and George C. Soulas \\ National Aeronautics and Space Administration \\ Glenn Research Center \\ Cleveland, Ohio 44135
}

\begin{abstract}
The NEXT propulsion system is an advanced ion propulsion system presently under development that is oriented towards robotic exploration of the solar system using solar electric power. The subsystem includes an ion engine, power processing unit, feed system components, and thruster gimbal. The Prototype Model engine PM1 was subjected to qualification-level environmental testing to demonstrate compatibility with environments representative of anticipated mission requirements. Thruster functional testing was performed before and after the vibration and thermal-vacuum tests. Random vibration testing, conducted with the thruster mated to the breadboard gimbal, was executed at $10.0 \mathrm{G}_{\mathrm{rms}}$ for 2 minutes in each of three axes. Thermal-vacuum testing included a deep cold soak of the engine to temperatures of $-168{ }^{\circ} \mathrm{C}$ and thermal cycling from -120 to $203{ }^{\circ} \mathrm{C}$. Although the testing was largely successful, several issues were identified including the fragmentation of potting cement on the discharge and neutralizer cathode heater terminations during vibration which led to abbreviated thermal testing, and generation of particulate contamination from manufacturing processes and engine materials. Thruster performance was nominal throughout the test program, with minor variations in some engine operating parameters likely caused by facility effects. Discharge cathode ignition times, however, were found to have a significant dependence on engine temperature. There were no significant changes in engine performance as characterized by engine operating parameters, ion optics performance measurements, and beam current density measurements, indicating no significant changes to the hardware as a result of the environmental testing. In general, the NEXT PM1 engine and the breadboard gimbal were found to be well-designed against environmental requirements based on the results reported herein, although there were issues uncovered during the testing. After resolution of the findings from this test program the hardware environmental qualification program can proceed with confidence.
\end{abstract}

\section{Introduction}

NEXT (NASA's Evolutionary Xenon Thruster) is an advanced ion propulsion system developed by a team led by the NASA Glenn Research Center (GRC) that is oriented towards robotic exploration of the solar system using solar electric power (Ref. 1). Potential mission destinations that could benefit from a NEXT solar electric propulsion system include inner planets, small bodies, and outer planets and their moons (Ref. 2). This range of robotic exploration missions generally calls for ion propulsion systems with deep throttling capability and system input power ranging from 5 to $25 \mathrm{~kW}$, as referenced to solar array output at 1 Astronomical Unit (AU). In order to ensure that the NEXT system can successfully perform these missions, its components will be subjected to qualificationlevel testing that is representative of the anticipated environments.

The NEXT ion propulsion subsystem development includes a 7-kW high efficiency ion thruster, modular power processing unit (PPU), advanced propellant management system (PMS), lightweight gimbal, and software algorithms for a digital control interface unit (DCIU). Individual components in a subsystem such as this are typically subjected to separate environmental test sequences, partially due to the different environments each will experience on a spacecraft. For the test program discussed in this paper, the thruster and gimbal were tested together as an assembly in vibration environments. The thruster was tested alone in thermal environments.

The NEXT ion thruster is a 7-kW, 36-cm-beam-diameter thruster with significant heritage to the 2.3-kW, 30-cm NSTAR engine which flew on the Deep Space 1 mission (Ref. 3) and is an integral part of the Dawn spacecraft scheduled for launch in Summer 2007 (Ref. 4). Initial thruster development work was led by GRC and included significant performance testing (Ref. 5), a 2000-hour wear test (Ref. 6), an integrated test with other subsystem components (Ref. 7), and more recently an ongoing wear test (Ref. 8) and a multi-thruster array test (Ref. 9). The thruster technology was transferred to NEXT industry partner Aerojet, which designed and fabricated a flight-like Prototype Model (PM) thruster (Ref. 10). Following performance acceptance testing at GRC (Ref. 11), the PM1 ion 
engine was sent to JPL for extensive environmental testing. First the engine was subjected to a thermal balance test (Ref. 12) in which the engine, instrumented with tens of thermocouples, was tested under a variety of operating conditions and thermal environments to characterize engine temperatures and thermal design margins. Data from that test were used in developing and validating an engine thermal model (Ref. 13). Following the thermal balance test the formal environmental test program described in this paper was initiated.

One of the JPL activities for the NEXT development project was development of a lightweight two-axis breadboard gimbal for the ion thruster. The breadboard gimbal is a lightweight, two-axis design using a four-bar linkage mechanism that provides a positive captured configuration for launch while providing for up to twenty degrees of thrust angle articulation while in the operational configuration (Ref. 14). JPL contracted with Swales Aerospace for the design and fabrication of two breadboard gimbals. The primarily-aluminum gimbal structure resembles an A-frame with titanium used for the flexures and the thruster mounts. An additional supporting bracket is required to support the mass of the gimbal motor. The breadboard gimbal was successfully subjected to vibration testing with a thruster mass model in an earlier test (Ref. 15).

The objectives of the environmental test program were as follows:

(1) To validate the NEXT PM1 thruster and breadboard gimbal assembly to qualification-level dynamic environments, including:

(a) Demonstrate thruster functionality pre- and post-vibe

(b) Demonstrate gimbal functionality pre- and post-vibe

(2) To validate the NEXT PM1 thruster to expected mission thermal environments, including standard qualification margins, including:

(a) Expose the thruster to expected mission temperatures in cycles

(b) Demonstrate thruster functionality pre- and post-test

Environmental test requirements for the thruster and gimbal were determined from the NEXT project requirements, expected mission environments, and JPL assembly-level environmental verification policies and requirements. Discussion of the test requirements may be found in Section II, along with test equipment and facility setup information, and test methods. Test results are presented in Section III.

\section{Test Setup and Methods}

\section{A. Test Article and Equipment}

\section{Thruster and Gimbal}

The thruster used for the environmental testing described herein was the NEXT Prototype Model 1 (PM1) thruster. The thruster was manufactured by Aerojet (Redmond, WA) under direction of the NASA Glenn Research Center. Significant changes in the PM thruster compared to the previous generation of thruster designs include new material coatings to increase emissivity for enhanced thermal margin, more uniform ion optics apertures, and a graphite discharge cathode keeper to mitigate keeper erosion. Additional information about the PM1 engine, including performance data, are presented in Reference 11.

Prior to the environmental testing the PM1 thruster was subjected to a thermal development test in which thruster internal temperatures were measured under a variety of engine operating conditions and environmental boundary conditions (Ref. 12). Following completion of that test program the engine was disassembled, inspected, and most of the thermocouples were removed. The six thermocouples that remained were one on each of the three engine gimbal pads, and three on the front mask.

Breadboard gimbal S/N 001 was used as the test article for the functional and vibration testing described herein. The breadboard gimbal was designed and fabricated to be flight-like, e.g. all fabricated parts were of JPL-approved materials with certifications. The motors chosen for the NEXT breadboard gimbal were ultra-high-vacuum class stepping motors. A flight unit would use space-rated versions with complete Quality Assurance documentation. The only functional difference between the two motor grades is the lower minimum temperature of the space-grade motor. The flight configuration of the gimbal has pinpullers specified as a launch lock for the actuator arm. This feature was not required for the breadboard gimbal, so a fixed-pin bracket was fabricated to replicate the launch lock function. All non-locking fasteners were locked or staked with Solithane, a flight-grade thread locking agent. All gimbal parts were demonstrated by analysis to meet allowable stress levels and minimum frequencies based on the predicted flight loads. Gimbal S/N 001 was vibrated with a thruster mass model under identical random vibration loads as to be used for the testing described herein (Ref. 15). 


\section{Vacuum Test Facility}

The thruster test portions of the PM1 environmental test program were conducted in the JPL Patio Chamber facility. The vacuum chamber is $3 \mathrm{~m}$ in diameter and $8.6 \mathrm{~m}$ long, with nine cyropumps installed and operational for this testing. With the vacuum chamber configuration used for this test, specifically the inclusion of the large engine thermal shroud, the effective pumping speed was approximately $160,000 \mathrm{~L} / \mathrm{s}$ on xenon. To minimize facility backsputter rates the interior of the vacuum facility is lined with graphite panels, which tended to absorb atmosphere gases and water vapor during the numerous vacuum cycles of the testing. Unfortunately, this led to modest tank pressure variations as the panels outgassed during thruster operation.

The thruster was installed in a 1.2-m diameter by $1.0-\mathrm{m}$ long cylindrical thermal shroud located at one end of the vacuum facility. The downstream end of the thermal shroud was located $6.2 \mathrm{~m}$ from the downstream end of the vacuum facility. The thruster was mounted inside the shroud with the neutralizer keeper orifice plate located $5.7 \mathrm{~cm}$ from the downstream end of the shroud. The cylindrical and rear thermal shroud walls were equipped with liquid nitrogen tubing to provide environmental cooling of the test article. The opening at the front of the shroud was equipped with a door made of multi-layer insulation. This door was opened during thruster operation and could be closed to minimize thermal interaction with the vacuum facility during non-operational cold soak periods.

The thermal shroud was also equipped with eight quartz infrared heat lamps to provide environmental heating to the thruster. The lamps were installed parallel to the thruster axis and spaced 45 degrees apart azimuthally with one end of the lamp even with the front mask of PM1. A temperature controller and SCR power controller were used for tight process control during temperature ramp and hold. A photograph of the thruster installed in the thermal shroud with the heat lamps operating is shown in Fig. 1. In contrast to the Thermal Development Test (Ref. 12) where the heat lamps were controlled through the heat flux coupons mounted near the engine, in the thermal vacuum test the heat lamps were directly controlled through the temperature of gimbal pad B. Gimbal pad B was located at the 10 o'clock position as viewed in Fig. 1; pads A and C were located at the 6 and 2 o'clock positions, respectively.

The thermal shroud and facility were equipped with many thermocouples for process control and monitoring. The thruster propellant lines internal to the thermal shroud were wrapped with heater tape, instrumented with thermocouples, and wrapped in an MLI blanket to control the temperature of the lines during thruster cold soaks and periods prior to engine startup.

Beam current density profiles were measured with two Faraday probes. The probes were installed on a stage that allowed them to translate through the thruster plume at axial distances between 0.045 and $0.55 \mathrm{~m}$ downstream of the thruster.

The environmental testing was performed using laboratory power supplies controlled and monitored by a data acquisition and control system. Cathode ignitor circuits were incorporated into the power supply rack and used for cathode ignition after the vibration test; prior to that the cathodes had been ignited by applying steady voltage to the keepers. Grid recycling was handled by a custom recycle circuit. Pressure, flow, and electrical instrumentation were calibrated prior to the thermal development test which was performed immediately

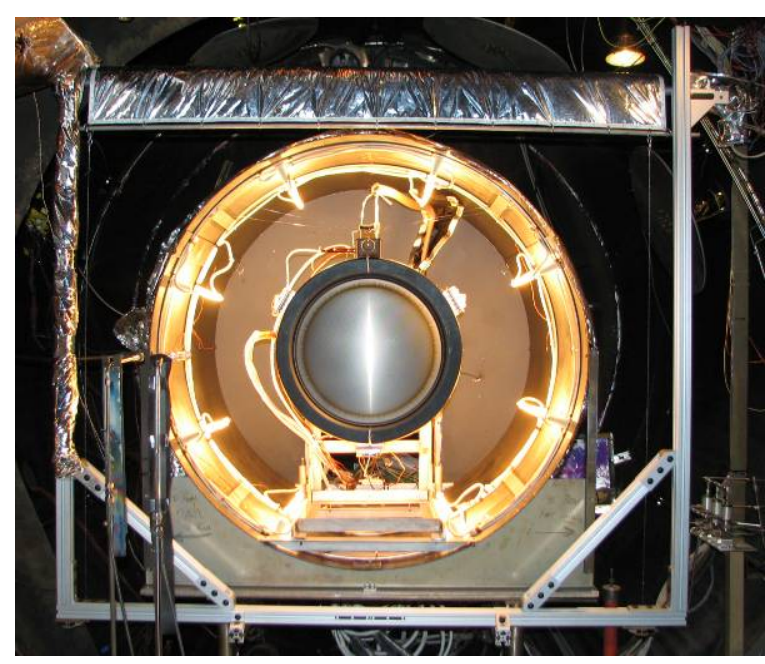

Fig. 1.-Test setup for functional and thermal vacuum testing. before the environmental testing.

The data acquisition system recorded thruster currents, voltages, flow rates and temperatures, and facility pressure and temperatures at a user-specified rate. Data were typically recorded once a minute; however, during thruster starts or when thruster parameters were being varied the rate was often changed to once every ten seconds. The software used to record data was also used to control thruster power supplies and flow rates. Closed-loop control of flow rates and beam current was used. 


\section{Vibration Test Setup and Facility}

The thruster was mated to the breadboard gimbal for vibration testing, as shown in the test setup photograph of Fig. 2. The thruster-gimbal assembly was mounted on a vibration fixture, comprised of a vibration test plate and three vibration test mounts, which provided the mechanical interface between the vibration table and the test article. The engine was fixed to the gimbal at each of the three gimbal legs. Each gimbal leg rested on a vibration test mount, and four piezoelectric three-axis force transducers were mounted between each test mount and the vibration test plate. These were used for vibration force limiting, discussed later. Gimbal legs were annotated the same as the thruster pads, i.e. leg A was located opposite the neutralizer.

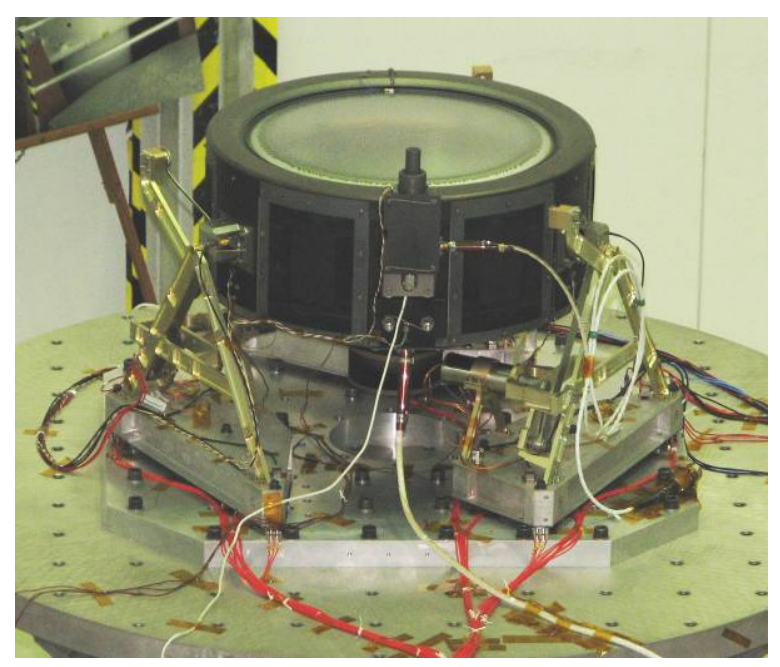

Fig. 2.-Test setup for $Z$-axis vibration.

The test assembly was instrumented with a total of seventeen tri-axial and one uniaxial response accelerometers. All accelerometers were bonded to Kapton (DuPont) tape applied to the test article surfaces. Nine tri-axials were mounted on the vibration test mounts near the gimbal strut attachment points. Three triaxials were located on the side of the gimbal brackets that mount to the thruster, and three other tri-axials were mounted on the thruster directly below the interface with the gimbal bracket. The remaining two tri-axials were mounted on the neutralizer and the neutralizer support pad, and the lone uni-axial accelerometer was mounted on the unperforated region of the accelerator grid directly opposite the neutralizer.

Vibration testing was performed in the JPL Dynamics Environmental Test Facility. Vertical (i.e. Z-axis, or thrust axis) excitation was performed on a Kimball head expander on the large spacecraft vibration test stand. Lateral (X- and Y-axis) excitation was performed on a large oil-lubricated slide plate. Application of vibration to the test article was controlled using one of JPL's $\mathrm{m}+\mathrm{p}$ vibration control systems. Vibration test control instrumentation consisted of two control accelerometers and one monitor accelerometer mounted to the vibration test plate. This was in conjunction with the signal from the twelve force transducers at the unit interface, controlling all random vibration tests using the extremal control mode. Data acquisition from control and response accelerometers was provided at a $20 \mathrm{kHz}$ sampling rate.

\section{B. Test Methods}

The environmental test program was performed in the sequence of steps shown in Table 1. Additionally, hardware inspection was performed prior to the first and after each of the test segments. This included visual inspection, electrical diagnostics, and in some cases disassembly of test hardware. Notable inspection results are described in the appropriate sections of this paper. Thruster and thruster/gimbal functional testing was performed prior to and after each test segment to demonstrate operation over requirements after exposure to environments.

\section{Thruster Functional Test}

Thruster functional testing was performed prior to the vibration testing to demonstrate nominal engine operation, including: engine performance, neutralizer characterization, electron backstreaming and perveance margins, double-to-single ion current ratios, and beam current density profile. Pre-vibration functional testing was also the first testing after disassembly of the thruster and removal of the significant thruster thermocouple instrumentation following the Thermal Development Test. Thruster functional testing was repeated after vibration testing and thermal-vacuum testing.

Table 1.-Environmental Test Sequence

\begin{tabular}{|c|l|}
\hline Sequence & \multicolumn{1}{|c|}{ Operation } \\
\hline 1 & Pre-Vibe Thruster Functional Test \\
2 & Pre-Vibe Gimbal Functional Test \\
3 & Random Vibration Tests \\
4 & Post-Vibe Gimbal Functional Test \\
5 & Post-Vibe Thruster Functional Test \\
6 & Thermal Vacuum Test \\
7 & Post-Thermal Thruster Functional Test \\
\hline
\end{tabular}


Testing of the NEXT PM1 thruster was conducted using laboratory power supplies and a laboratory flow system. A total of four Functional Test Points (FTP) were used during the environmental testing; the thruster controlled parameters are listed in Table 2 for those conditions as well as the startup conditions (i.e. Discharge-Only). Seven parameters were specified for a given operating condition: the propellant flow rates to the discharge chamber, cathode, and neutralizer; the extraction parameters beam current, beam voltage, and accelerator grid voltage; and the neutralizer keeper current. Note that in practice it was the screen power supply voltage that was controlled and the beam voltage was calculated from the sum of the power supply voltage and the neutralizer floating voltage. Beam current was controlled by adjusting the discharge current, often performed automatically with closed-loop control through the data acquisition and control system. Operating conditions are referenced in this report by the combination of beam current and voltage.

Table 2.-Thruster Controlled Parameters for Functional Testing

\begin{tabular}{|c|c|c|c|c|c|}
\hline Control Parameter & Discharge-Only & FTP 1 & FTP 2 & FTP 3 & FTP4 \\
\hline Beam Current (A) & - & 1.20 & 2.00 & 3.52 & 3.52 \\
Beam Voltage (V) & - & 679 & 1179 & 1179 & 1800 \\
Accelerator Voltage (V) & - & -115 & -200 & -200 & -210 \\
Neutralizer Keeper Current (A) & 3.0 & 3.0 & 3.0 & 3.0 & 3.0 \\
Main Flow Rate (sccm) & 14.23 & 14.23 & 25.79 & 49.64 & 49.64 \\
Cathode Flow Rate (sccm) & 3.57 & 3.57 & 3.87 & 4.87 & 4.87 \\
Neutralizer Flow Rate (sccm) & 6.00 & 3.00 & 2.50 & 4.01 & 4.01 \\
\hline
\end{tabular}

Thruster operating parameters were continuously recorded by the data acquisition system during the thruster functional performance testing. In addition to the controlled parameters, the following parameters were recorded: accelerator grid current, discharge current and voltage, cathode keeper voltage, neutralizer keeper voltage, neutralizer-common-to-ground voltage, and tank pressure. Common calculated or derived parameters were also determined: thrust, specific impulse, total efficiency, and beam ion energy cost (also called discharge losses). Floating (i.e. neutralizer coupling) voltages were in the range of -10.5 to $-11.5 \mathrm{~V}$ for this testing.

For the pre-vibration functional testing the discharge and neutralizer cathodes were started by application of a constant $150 \mathrm{~V}$ to the keepers until ignition, at which point the power supplies automatically went into currentlimited mode at the current set points. For subsequent functional testing, dedicated cathode ignitor circuits were used to apply rapid high-voltage pulses for plasma discharge ignition.

Ion optics performance was measured using standard procedures. Perveance measurements were made by holding the beam current and accelerator grid voltage constant while varying the screen grid voltage and recording the accelerator grid current. The discharge current was adjusted in this case to maintain constant beam current. The perveance limit was defined as the total voltage at which the rate-of-change of accelerator grid current was $0.02 \mathrm{~mA} / \mathrm{V}$. Electron backstreaming (EBS) onset was determined by reducing the magnitude of the accelerator grid voltage at constant discharge current and monitoring the beam current. A 1-mA increase in the beam current from the lowest current achieved during the measurement defined the EBS limit. In practice, the voltage drop across the calibrated beam current shunt resistor was used to determine this limit.

Neutralizer characterization was performed in the discharge-only mode conditions shown in Table 2 by decreasing the neutralizer flow rate until the neutralizer transitioned from spot to plume mode. Plume mode, characterized by electrical oscillations in the neutralizer keeper circuit, was defined as reaching or exceeding $5 \mathrm{~V}$ peak-to-peak oscillations measured between neutralizer keeper and neutralizer common.

\section{Gimbal Functional Test}

Gimbal functional testing was performed with the thruster integrated onto the gimbal and the assembly mounted to the vibration test fixturing. Since the gimbal is a zero-G design that cannot adequately support and drive the thruster mass in a one-G environment, the thruster-gimbal assembly was fitted with a system of weights and pulleys for functional testing to offload the thruster mass. Offloading was applied equally at each gimbal pad through a fastener attached to each gimbal thruster bracket as shown in Fig. 3. The gimbal was driven via a custom software program and dedicated motor control hardware. 
Functional testing was accomplished by driving the gimbal to a range of nineteen positions which described and circumscribed the range of motion. At several of the sequence steps, an inclinometer was used to measure the gimbal pitch in two orthogonal axes. Accuracy of the inclinometer measurement was estimated to be $\pm 0.5^{\circ}$ and all measurements were rounded to the nearest degree. After returning to the stowed position, the pin-puller mockups were re-inserted into the assembly and their fit used to determine if the stepper motors returned to the correct final position (i.e. there were no missed steps during the functional test).

\section{Vibration Test}

The random vibration specification for the NEXT gimbal and thruster assembly was based on Delta-class launch vehicles and typical locations of electric propulsion hardware on spacecraft. The qualification-level specification, shown in Table 3 , has a total level of $10.0 \mathrm{G}_{\mathrm{rms}}$ and calls for random vibration testing in each of three orthogonal axes for a duration of two minutes per axis. Sine surveys were performed before and after each full-

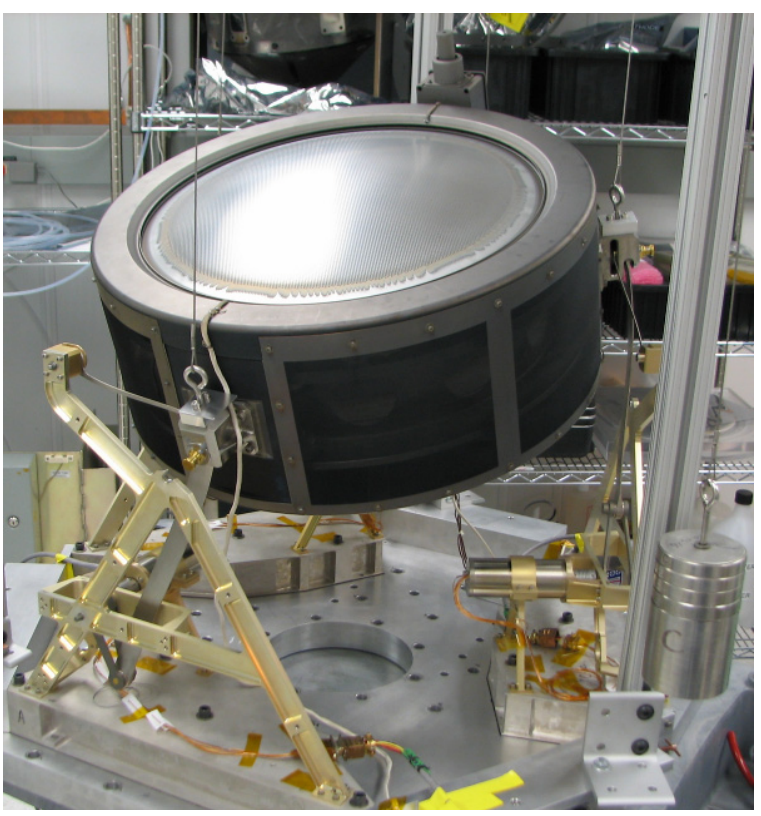

Fig. 3.-Gimbal functional test. level random vibration test to identify hardware changes caused by testing. The surveys were run at a load of $0.25 \mathrm{G}_{0-\mathrm{pk}}$ from 5 to $2000 \mathrm{~Hz}$ at a sweep rate of two octaves per minute.

Vibration testing of the NEXT gimbal also incorporated the practice of force-limited vibration testing which is used for most vibration tests performed at JPL. Force-limiting during vibration testing guards against artificial test failures caused by overtesting, a result of the infinite mechanical impedance of the shaker and the use of only acceleration-based control (Ref. 16). In this situation, the reaction forces at the fixture/engine interface can become unrealistically high compared to a flight environment at test article resonances. In a force-limited test, real-time force measurement and limiting is performed to notch the input acceleration spectrum.

Vibration testing in the Z-axis (i.e. thrust axis) was performed first, followed by the lateral axes Y (i.e. axis intersecting both the discharge chamber and neutralizer centerlines) and finally X. After the Z-axis testing was completed the test assembly including vibration fixturing was removed from the head expander, the facility was reconfigured for lateral axis testing, and the test assembly attached to the slip plate. For all axes, the first activity was a sine survey of the assembly. This was followed by a random vibration test at a level of $-18 \mathrm{~dB}$ with respect to the full random vibration loads shown in Table 3 in order to verify instrumentation operation and tune the vibration force-limiting algorithms. A $6 \mathrm{~dB}$ intermediate-level run was performed before the two-minute random vibration test at the full load, which was followed by a post-random sine survey. Physical inspections of the test assembly were performed after each of these tests.

\section{Table 3.-Qualification-Level Random} Vibration Requirements.

\begin{tabular}{|c|c|}
\hline Frequency $(\mathrm{Hz})$ & Level \\
\hline $20 \mathrm{~Hz}$ & $0.04 \mathrm{~g}^{2} / \mathrm{Hz}$ \\
$20-50 \mathrm{~Hz}$ & $+3 \mathrm{~dB} /$ octave \\
$50-600 \mathrm{~Hz}$ & $0.1 \mathrm{~g}^{2} / \mathrm{Hz}$ \\
$600-2,000 \mathrm{~Hz}$ & $-6 \mathrm{~dB} / \mathrm{Octave}$ \\
$2000 \mathrm{~Hz}$ & $0.009 \mathrm{~g}^{2} / \mathrm{Hz}$ \\
Overall & $10.0 \mathrm{G}_{\mathrm{rms}}$ \\
\hline
\end{tabular}

Duration: 2 min./axis, 3 orthogonal axes

\section{Thermal Vacuum Test}

Requirements for the thermal vacuum test were derived from mission studies and simple spacecraft configuration models. The NEXT system design has been driven by Deep Space Design Reference Missions as well as by Discovery and New Frontiers class missions (Ref. 17). Preliminary modeling of the NEXT PM-design thruster on a sample spacecraft configuration showed that the most aggressive thermal conditions were projected to occur during Venus gravity assists on trajectories to Saturn and Neptune, specifically at 0.85 A.U. and with a solar incidence angle of $38^{\circ}$ from the thruster exit plane (Ref. 10). A more rigorous thermal model of the NEXT thruster was recently developed in conjunction with the PM1 Thermal Development Test (Ref. 12) and validated with data from that test (Ref. 13). 
A departure from standard practice was made with the selection of reference temperature location on the NEXT engine. On the Deep Space 1 mission, a location on the front mask of the NSTAR ion engine was used as the reference temperature location for environmental testing and flight telemetry (Ref. 18). It was very difficult, however, to correlate the reference location temperature with the internal thruster temperatures because the mask was not well coupled to the engine through thermal conduction and knowledge of the surface optical properties was poor. Evaluation of data from the NEXT PM1 Thermal Development Test combined with the thermal model of the engine suggested that the engine gimbal pads would be a more appropriate location for temperature reference.

The NEXT PM1 thermal model was employed in a simple spacecraft configuration model at the projected mission worst-case solar irradiance to determine maximum expected gimbal pad temperatures in this environment. Preliminary results of that work indicated that a gimbal pad temperature of $183{ }^{\circ} \mathrm{C}$ would be expected, yielding a thermal-vacuum test maximum temperature of $203{ }^{\circ} \mathrm{C}$ including the standard flight temperature margin. (Note that recent refinements in the model have suggested maximum temperature of $187^{\circ} \mathrm{C}$ under these conditions (Ref. 13), indicating a higher maximum temperature may be required for future development testing.) The cold temperature limit for NEXT thermal-vacuum testing was not derived from corresponding mission analyses and thermal modeling; ion thrusters can survive much lower temperatures than the $-100{ }^{\circ} \mathrm{C}$ levels typically required for flight systems. For the testing described herein, a cold temperature of $-120^{\circ} \mathrm{C}$ was chosen which was $11{ }^{\circ} \mathrm{C}$ colder than the Deep Space 1 qualification requirement for the NSTAR ion engine (Ref. 18).

The plan for the thermal vacuum test was to perform three identical thermal cycles (as will be shown later, only two cycles were actually performed). The cycles consisted of:

(1) Two-hour cold soak after reaching the cold temperature limit of $-120^{\circ} \mathrm{C}$.

(2) Short-duration operation in discharge-only mode at full-power conditions.

(3) Full-power operation ramp to the hot temperature limit of $203^{\circ} \mathrm{C}$.

(4) Two hours of operation at full power (3.52 A and $1800 \mathrm{~V})$.

(5) Two hours of operation at mid power (3.52 A and $1179 \mathrm{~V})$.

(6) Turn off engine, then immediately begin cathode ignition sequence.

(7) Short-duration operation in discharge-only mode, then at full power conditions.

(8) Turn off engine and cool for next cycle.

A schematic of the test profile is shown in Fig. 4. In this test profile, three cold starts and three hot starts were planned. The planned total cumulative cold soak time was 6 hours and total cumulative hot operation time was 12.5 hours. All discharge-only operation during thermal-vacuum testing was performed at discharge conditions equivalent to full power operation (i.e. $3.52 \mathrm{~A}$ and $1800 \mathrm{~V}$ ).

Engine operating parameters were recorded continually throughout the test as described in Section II. After approximately 90 minutes of operation at each of the two beam extraction operating points, electron backstreaming data were acquired. It was also planned to acquire beam current density data with the Faraday probes, but after the first scan during the first thermal cycle the stage system malfunctioned and no more data could be acquired.

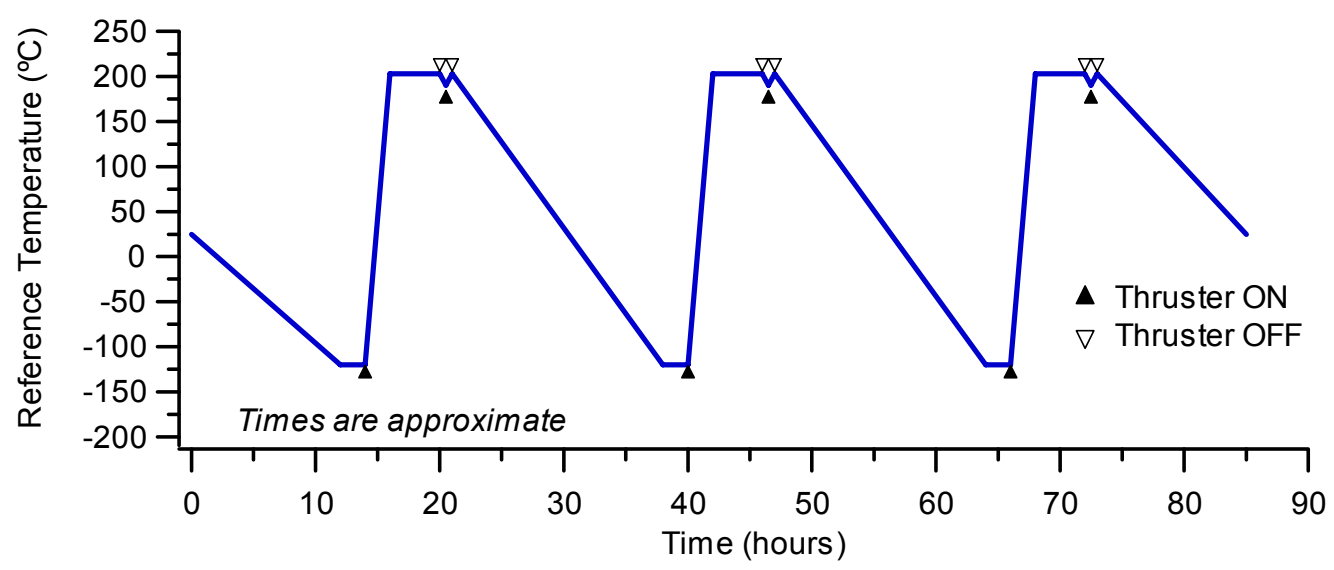

Fig. 4.-Thermal vacuum test plan temperature profile. 


\section{Test Results}

\section{A. Pre-Vibration Thruster Functional Test}

Thruster functional testing was performed at the beginning of the environmental test program to establish a baseline against which post-environmental performance could be compared. Non-controlled and derived engine performance parameters for the highest power and a mid power operating condition are compared in Table 4 for the Performance Acceptance Test (PAT) conducted at GRC (Ref. 11) and the pre-vibration functional test along with ion optics performance measurements. The modest differences in the discharge voltage and accelerator grid current are almost certainly due to differences in the tank pressures between the two facilities in which these tests were run (about a factor of 3.5 lower in the GRC facility at full power). Note that at higher background pressures there is more mass ingestion into the discharge chamber, and standard operating procedure for the NEXT test program is not to correct the main flow into the thruster for ingestion. Apart from these parameters, there was no significant difference observed in the engine performance data. Ion optics performance margins were the same within measurement error with the exception of a notable difference in perveance margin at the $2.0 \mathrm{~A}, 1179 \mathrm{~V}$ operating condition. Though this numerical comparison appears to indicate a difference somewhat larger than the nominal measurement error, direct comparison of the data used to infer the perveance limit suggest that there were no significant differences in optics performance at this condition and that the numerical differences were due to relatively large voltage steps used when acquiring data near the limit in one case.

Table 4.-Comparison of Engine Performance Data from Initial Performance Acceptance Test (PAT) (Ref. 11) and Pre-Vibration Functional Test

\begin{tabular}{|l|c|c|c|c|}
\hline & \multicolumn{2}{|c|}{$3.52 \mathrm{~A}, 1800 \mathrm{~V}$} & \multicolumn{2}{c|}{$2.0 \mathrm{~A}, 1179 \mathrm{~V}$} \\
\hline Parameter & $\begin{array}{c}\text { Initial } \\
\text { PAT }\end{array}$ & Pre-Vibe & $\begin{array}{c}\text { Initial } \\
\text { PAT }\end{array}$ & Pre-Vibe \\
\hline Discharge Current (A) & 18.4 & 18.1 & 13.8 & 13.9 \\
Discharge Voltage (V) & 24.3 & 23.2 & 24.7 & 24.5 \\
Cathode Keeper Voltage (V) & 5.3 & 5.4 & 3.9 & 3.9 \\
Accelerator Grid Current (mA) & 14.5 & 20.8 & 6.1 & 7.2 \\
Neutralizer Keeper Voltage (V) & 12.1 & 12.0 & 13.7 & 13.3 \\
Power (W) & 6860 & 6860 & 2750 & 2760 \\
Thrust (mN) & 237 & 238 & 108 & 109 \\
Specific Impulse (sec) & 4190 & 4190 & 3490 & 3500 \\
Total Efficiency & 0.710 & 0.712 & 0.675 & 0.677 \\
perveance Margin (V) & 1150 & 1156 & 720 & 686 \\
Electron Backstreaming Margin (V) & 43 & 49 & 97 & 101 \\
\hline
\end{tabular}

\section{B. Pre-Vibration Gimbal Functional Test}

Starting from the stowed position, the gimbal was first driven to the "clear latch" position to ensure that the thruster pins cleared the gimbal A-frames acceptably. The gimbal was then driven to each of the positions shown in Table 5 and the inclination was measured at gimbal thruster bracket A (i.e. the gimbal bracket attached to the thruster, located opposite the neutralizer) in the radial and tangential directions. The total range of the gimbal at this bracket was measured as $-19^{\circ} / 20^{\circ}$ in the radial direction and $\pm 17^{\circ}$ in the tangential direction. The full nineteen-step drive program was then successfully performed to exercise the gimbal motion with the attached thruster. Following completion of the sequence, the pin-puller mockups were re-inserted into the gimbal demonstrating successful and complete return to the stowed and latched position.

\section{Thruster/Gimbal Assembly Vibration Test}

\section{Z-Axis Testing}

Dynamic testing began with the Z-axis (i.e. thrust-axis) testing, shown in the photograph of Fig. 2. Initial tests and then the two-minute full random vibration test were completed without incident. The vibration test inputs, which were notched automatically and in real time during the test according to the force limit specifications, are shown in Fig. 5. Significant notches were observed at 100, 750, and $1150 \mathrm{~Hz}$. 
Table 5.-Pre-Vibe Gimbal Articulation Measurement Results

\begin{tabular}{|c|c|c|c|}
\hline Position Name & $\begin{array}{c}\text { Gimbal Pad A } \\
\text { Elevation }(\mathrm{cm})\end{array}$ & $\begin{array}{c}\text { Radial } \\
\text { Inclination }\end{array}$ & $\begin{array}{c}\text { Tangential } \\
\text { Inclination }\end{array}$ \\
\hline Stowed, Latched & 0 & $0^{\circ}$ & $0^{\circ}$ \\
Clear Latch & 2 & $0^{\circ}$ & $0^{\circ}$ \\
Mid Plane & 10 & $0^{\circ}$ & $0^{\circ}$ \\
Max A, Level B, Level C & 17 & $-8^{\circ}$ & $0^{\circ}$ \\
Max A, Min B,C & 17 & $-19^{\circ}$ & $0^{\circ}$ \\
Min A, Max B,C & 1 & $20^{\circ}$ & $0^{\circ}$ \\
Mid Plane & 10 & $0^{\circ}$ & $0^{\circ}$ \\
Level A, Min B, Max C & 10 & $0^{\circ}$ & $17^{\circ}$ \\
Level A, Max B, Min C & 10 & $-1^{\circ}$ & $-17^{\circ}$ \\
Stowed, Latched & 0 & $0^{\circ}$ & $0^{\circ}$ \\
\hline
\end{tabular}

Inspection of the test article immediately after the full-level test revealed a large amount of debris and particulate contamination in the bottom of the thruster plasma screen cone. This debris was eventually traced to fragmentation of potting cement on the discharge cathode heater electrical termination. Particulate dust was also observed within the plasma screen, on the discharge chamber stiffening ring near the gimbal pads.

Electrical inspection of the engine after the Z-axis testing revealed significant changes in the discharge cathode heater resistance. The heater resistance increased from its nominal value, as measured prior to the full test, by a factor of seventeen, well out of specification. No significant changes were noted in the neutralizer heater resistance. The discharge cathode heater resistance continued to vary appreciably throughout the vibration testing, and was later correlated to the potting cement fragmentation.

Comparison of the pre- and post-vibe sine surveys showed significant changes on some locations of the test assembly near the fundamental mode. One of the largest changes, shown in Fig. 6, was observed on the gimbal thruster bracket at leg C. Two different effects are observed near $100 \mathrm{~Hz}$, a small change in frequency and a significant damping of the response. The observed frequency shift of roughly 5 percent is within what is nominally observed in run-to-run comparison. The change in damping is not necessarily an indicator for a serious problem but may be, for example, a fastener loosening somewhat. The two issues are not necessarily the same and could result from different effects. Similar changes were observed in the accelerometer mounted on the thruster gimbal pad, on the other side of the gimbal-thruster interface from the data of Fig. 6.

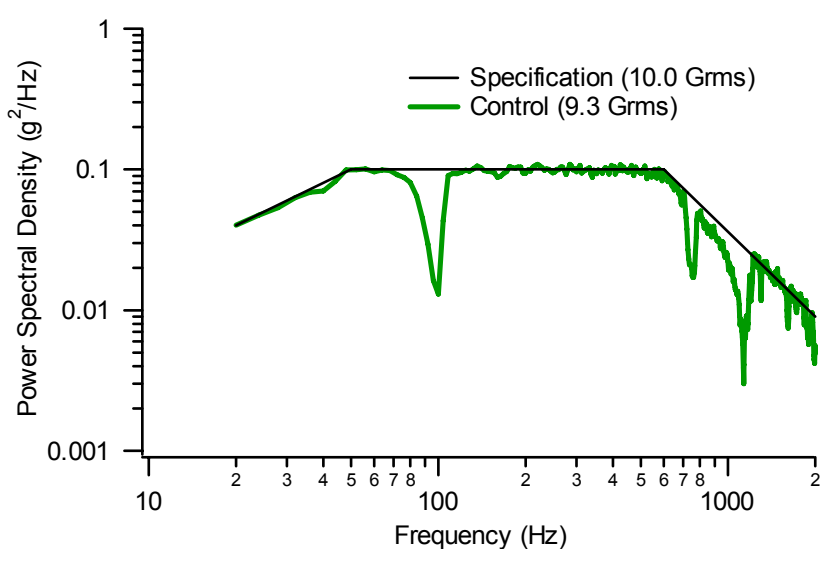

Fig. 5.-Comparison of random vibration specification with force-limited test inputs, Z-axis excitation.

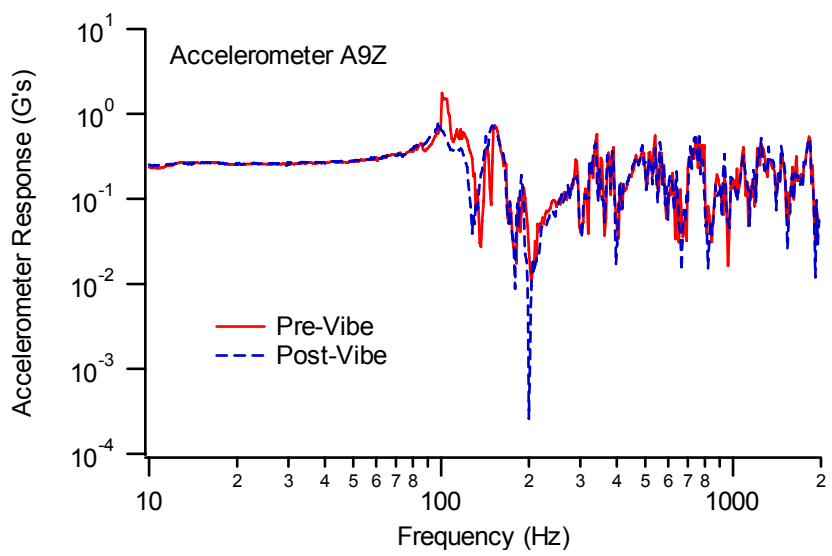

Fig. 6.-Comparison of sine survey results before and after full-level $Z$-axis random vibration, gimbal thruster bracket leg $\mathrm{C}$. 
In contrast to the changes observed at leg $\mathrm{C}$, there was little change observed in the data from accelerometers location near the other two gimbal thruster brackets on legs A and B. Moderate differences in sine surveys were seen in the other accelerometers located on the engine. There was little if any change in the sine survey data for the accelerometers on the vibration test mounts, as shown in the representative data of Fig. 7. These results collectively indicate that changes occurred in the test article near the thruster/gimbal interface at leg $\mathrm{C}$ and not at the structural bolting interface between the vibration fixturing and the vibe table. Taken by themselves, the sine survey shifts are not especially troubling but when combined with the other observed thruster anomalies they required further review.

Inspection of the test assembly immediately after the Z-axis testing did not reveal any clear causes for the sine survey shifts observed in the data. After removal from the vibration table, a torque check was performed on the test assembly fasteners. Slight loosening was observed on the stabilizer arm fasteners of gimbal legs B and C. Also observed was a slight rotation in the thruster pin at leg A. The fasteners joining the thruster and gimbal had not loosened.

Additional review of the sine survey data after conclusion of the vibration testing suggested that hardware changes occurred in the main load path near gimbal pad C. Changes in sine survey data for accelerometers at gimbal pad C were similar, and were much larger than those observed for the accelerometers at pads A and B. It is likely that the source of the shift was between the accelerometer on the gimbal thruster bracket and the gimbal mounting plate, but it is also possible that the source was internal to the thruster in the load path of the gimbal bracket. During thruster disassembly and inspection after the completion of the environmental test program, however, there was no evidence of a cause for a sine survey shift in the thruster hardware. At this point, investigation of the sine survey shift was concluded with the most likely cause a slight settling in the hardware at the leg $\mathrm{C}$ thruster gimbal bracket.

\section{Lateral Axis Testing}

Dynamic testing continued with the Y-axis testing. The test setup is shown in the photograph of Fig. 8 . The Y-axis testing proceeded nominally until an intermediate-level random vibration test in which a loose fastener on the thruster plasma screen was observed and the test was aborted. The torque on all plasma screen fasteners was checked after this test and three were found to have loosened noticeably. It is likely that some of this loosening occurred during the $\mathrm{Z}$-axis testing but was not observed until this time. After tightening the loose fasteners and repeating the pre-random sine survey, the two-minute full random vibration test was completed without incident.

After completion of the $\mathrm{Y}$-axis testing the test assembly shown in Fig. 8 was rotated $90^{\circ}$ to perform the $\mathrm{X}$-axis random vibration testing. The $\mathrm{X}$-axis test sequence including the two-minute full random vibration test was completed without incident. The vibration test inputs for both $\mathrm{X}$ and $\mathrm{Y}$ excitation are shown in Fig. 9. Significant notches in the control acceleration spectrum were observed at 80 and $390 \mathrm{~Hz}$ for the $\mathrm{Y}$-axis excitation, and at 82,380 , and $1150 \mathrm{~Hz}$ for $\mathrm{X}$-axis excitation.

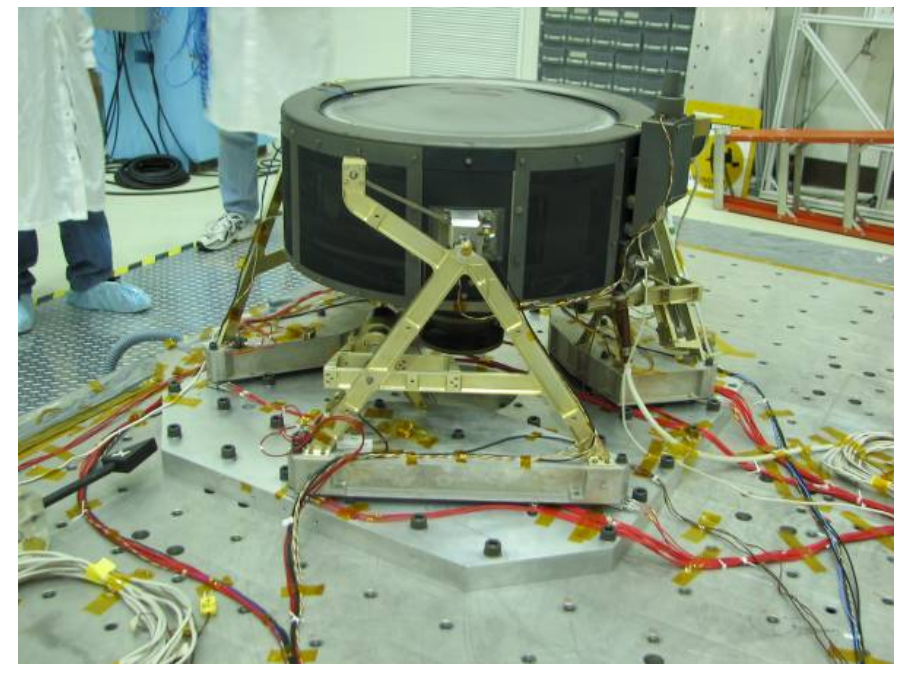

Fig. 8.-Test setup for Y-axis vibration. 


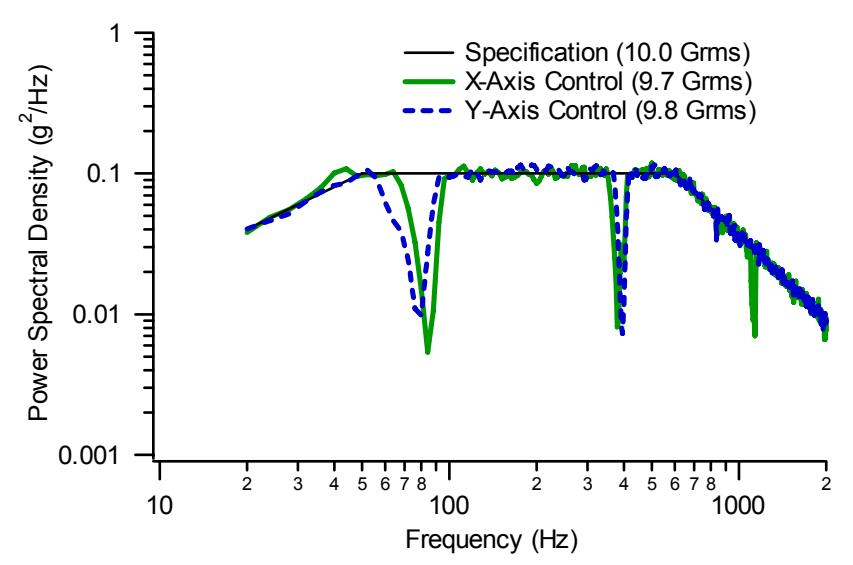

Fig. 9.-Comparison of random vibration specification with force-limited test inputs, lateral axis excitation.

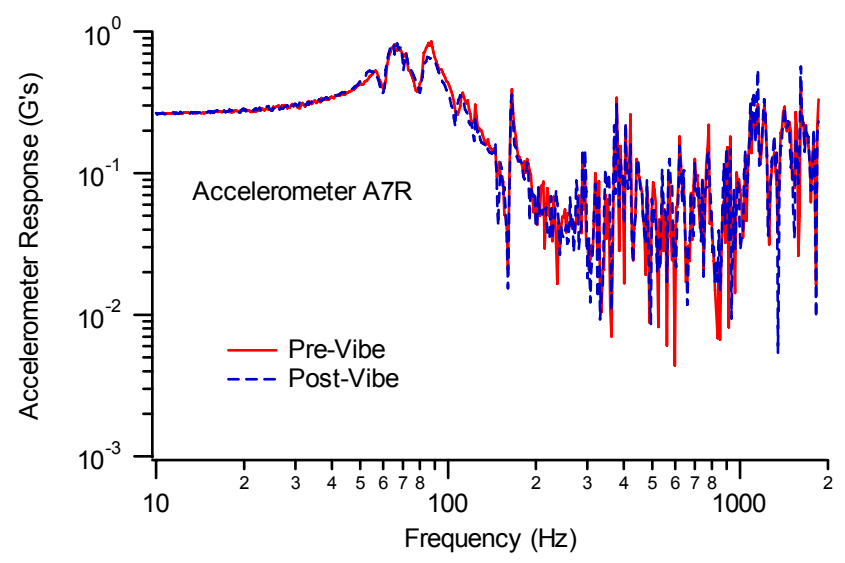

Fig. 10.-Comparison of sine survey results before and after full-level $\mathrm{Y}$-axis random vibration, gimbal thruster bracket leg $\mathrm{A}$.
Physical inspection of the test assembly after the $\mathrm{Y}$-axis testing indicated some slight movement in the thruster pin at gimbal leg B, with no other significant findings. Likewise, slight movement of thruster pins at gimbal legs B and C was observed after $\mathrm{X}$-axis testing with no other significant findings.

Electrical inspection of the test assembly after the $\mathrm{Y}$-axis testing revealed that, in addition to variations in the discharge cathode heater resistance, the neutralizer heater resistance had increased from the nominal value measured before the test to open-circuit as measured by a digital multimeter, indicating a physical heater failure caused by $\mathrm{Y}$-axis vibration testing. Tapping of the neutralizer housing with a plastic tool caused considerable resistance changes with each tap, suggesting a loose electrical connection. After completion of the $\mathrm{X}$-axis vibration testing, both discharge and neutralizer heaters were found to be open circuit.

Comparison of the $\mathrm{Y}$-axis pre- and post-vibe sine surveys showed minor changes on the test assembly near the fundamental mode in the frequency range of 50-100 Hz. Typical data are shown in Fig. 10; similar differences were observed throughout the other accelerometers on the test article. Minor changes near the fundamental mode were also observed after $\mathrm{X}$-axis testing among the accelerometers located on the test article. These sine survey differences are considered to be quite minor and are not an indication of a significant change in the test hardware. As for the Z-axis results, the accelerometers on the vibration test mounts did not show any significant difference for either Y-axis or

$\mathrm{X}$-axis testing. This result is an indication that changes occurred in the test article and not at the structural bolting interface between the vibration fixturing and the vibe table.

Physical inspection of the test article before removal from the vibration table following X-axis testing showed no evidence of loosening of any fasteners on the gimbal stabilizer arms, thruster plasma screen, or the twelve fasteners joining the thruster and gimbal. Torque on the twelve bolts fastening the vibration test mounts to the vibration test plate through the force transducers was checked and found to be the same as the installation torque (i.e. no loosening was observed).

\section{Post-Vibration Inspection Results}

The thruster/gimbal assembly was given an extensive inspection following the completion of the vibration testing. There were no significant additional findings as a part this inspection, though contamination and cathode heater resistance findings were followed up in greater detail. In many instances the amount of contamination generated was in excess of typical spacecraft cleanliness requirements.

The interior of the thruster discharge chamber was visually inspected through the ion optics and a significant amount of particulate contamination was observed. The material appeared to be a white fine-granular powder concentrated near the discharge cathode on either side of the cathode magnet ring, as shown in Fig. 11. The material was later sampled and shown to be residue from a mechanical fabrication treatment applied to the discharge chamber during engine fabrication. 
Internal surfaces of the thruster were inspected by removing a portion of the cylindrical plasma screen. Most of the particulate dust that was observed after Z-axis testing appeared to have been shaken off during the subsequent lateral axis testing, but some particulates remained on the discharge chamber stiffening ring surfaces. Visible particulate material was sampled and the composition was determined to be a mixture of metallic particles, residue from fabrication processes, and loose fibers. The fibers were positively identified as a match to the fiberglass sleeving on the internal thruster wiring. Metallic residue was traced to debris from nut plate galling.

The cover plate of the neutralizer assembly was removed as a part of the post-test inspection to investigate the cause of the heater resistance variations. Debris of various sizes was observed at the bottom of the housing not unlike the debris seen at the bottom of the plasma screen during Z-axis vibration testing. The heater termination area showed significant loss of cement potting compound, clearly the source of the observed debris. This

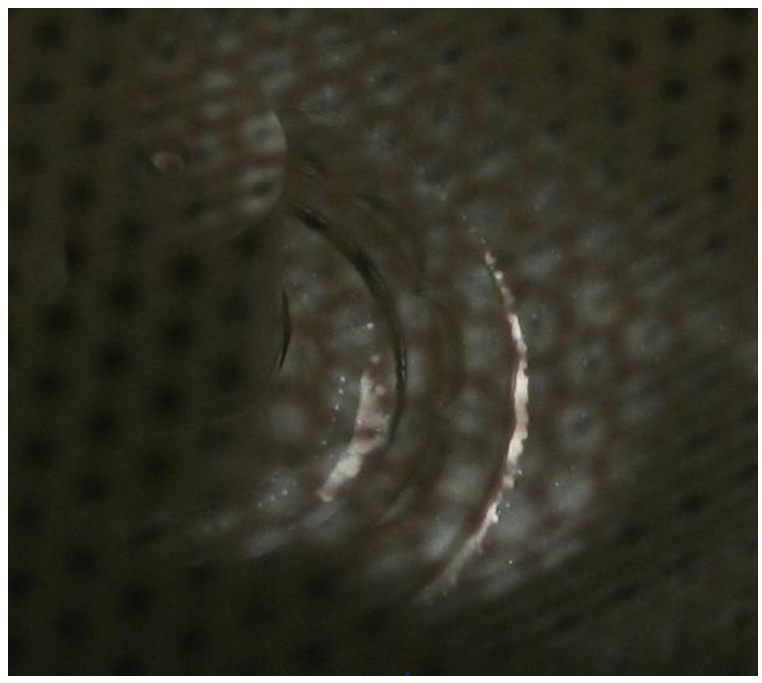

Fig. 11. Discharge Chamber Particulate Contamination (photographed through ion optics). indicated, and a full inspection later confirmed, that the debris found in the plasma screen cone during Z-axis vibration resulted from freed potting cement on the discharge cathode assembly. Inspection of the neutralizer low-voltage propellant isolator revealed no visible cracks or other anomalies. Inspection through the housing downstream aperture toward the cathode and keeper orifice plates revealed nothing of note, but visual access was limited.

\section{Post-Vibration Gimbal Functional Test}

Gimbal functional testing was repeated in the same manner that it had been performed in the pre-vibration characterization. The gimbal was driven to each of the positions shown in Table 5 and the inclination was measured at gimbal thruster bracket $\mathrm{A}$ in the radial and tangential directions. All measurements were identical to the pre-vibe measurements of Table 5 with the exception of the radial inclination in the "Level A, Max B, Min C" step which was $-1^{\circ}$ in the pre-vibe test and $0^{\circ}$ in the post-vibe test. This is within the uncertainty of the measurement and the rounding applied to the data. The total range of the gimbal at this bracket was measured as $-19^{\circ} / 20^{\circ}$ in the radial direction and $\pm 17^{\circ}$ in the tangential direction, identical to the pre-vibration measurement. The full nineteen-step drive program was then successfully performed to exercise the gimbal motion with the attached thruster. Following completion of the sequence, the pin-puller mockups were re-inserted into the gimbal demonstrating successful and complete return to the stowed and latched position. There was no indication from inspection or test that the gimbal performed any differently after vibration than it did before vibration.

\section{E. Post-Vibration Thruster Functional Test}

The post-vibration thruster functional testing was conducted in the same manner as the pre-vibration testing. Cathode heater continuity was achieved by applying short-duration pulses of moderate voltage and current to the heaters, after which nominal resistance was restored. There were no significant differences in engine performance as compared to the pre-vibration testing. Detailed comparisons of performance data are shown in Section G.

\section{F. Thruster Thermal-Vacuum Test}

Immediately upon conclusion of the post-vibration engine performance testing, LN2 flow to the thermal shroud was initiated and the shroud door was closed to begin an extended cold soak of the engine. After 114 hours of soaking the engine reached temperatures of -168.1 to $-168.6{ }^{\circ} \mathrm{C}$ on the gimbal pads and -167.4 to $167.5^{\circ} \mathrm{C}$ on the front mask. The engine was demonstrated to start nominally after this soak and was operated in discharge-only mode for approximately thirty minutes before it was shut down. Following this, a non-operational thermal cycle was performed. The thermal shroud heat lamps were turned on and the reference temperature location (gimbal pad B) was brought from $66{ }^{\circ} \mathrm{C}$ to the control temperature of $203{ }^{\circ} \mathrm{C}$ in about 100 minutes, where it was held for 152 minutes before turning off the lamps. 
The first thermal cycle was performed following engine cool down initiated the previous day. The cathode ignition process was initiated two hours after the reference temperature cooled to the target of $-120^{\circ} \mathrm{C}$. The engine started nominally and was brought to full power per the test plan. Heat lamp power was then turned on and the temperature reference location ramped to the $203{ }^{\circ} \mathrm{C}$ control temperature in 46 minutes. Thruster operation was held steady at full power $(3.52 \mathrm{~A}, 1800 \mathrm{~V})$ and at the control temperature for 134 minutes before transitioning to the lower power point $(3.52 \mathrm{~A}, 1179 \mathrm{~V})$. After 125 minutes of operation at this condition the thruster was shut down and the cathode heaters immediately turned on for the hot start. The hot start was nominal and the engine operated in discharge-only mode per the test plan and then at full power before finally turning the engine off. The engine and thermal shroud were allowed to cool for the next thermal cycle. Performance data obtained during the thermal cycles are discussed in a subsequent section. The temperature history for all of the thermal-vacuum testing is shown in Fig. 12. Note that the coolest of the three gimbal pads was chosen for the control thermocouple, hence the temperatures of the other two gimbal pads were higher than the $203^{\circ} \mathrm{C}$ control temperature as seen in the figure.

The second thermal cycle was performed on the subsequent day. The cathode ignition process was initiated two hours after the reference temperature cooled to the target of $-120^{\circ} \mathrm{C}$. The engine started nominally and was brought to full power per the test plan. Heat lamp power was turned on and the temperature reference location ramped to the $203{ }^{\circ} \mathrm{C}$ control temperature in 48 minutes. Thruster operation was held steady at full power and the control temperature for 133 minutes before transitioning to the lower power. After 120 minutes of operation at this condition the thruster was shut down and the cathode heaters immediately turned on for the hot start. The hot start was nominal and the engine operated in discharge-only mode per the test plan then at full power before finally turning the engine off. The engine and thermal shroud were allowed to cool for the next thermal cycle.

On the third day of thermal-vacuum testing the neutralizer heater failed open-circuit when attempting to perform the cold start. After application of environmental heating (i.e. discharge-only operation and low-level lamp heating) for 38 minutes the neutralizer heater was able to operate. At this point it was decided to skip the third thermal cycle and proceed to functional testing.

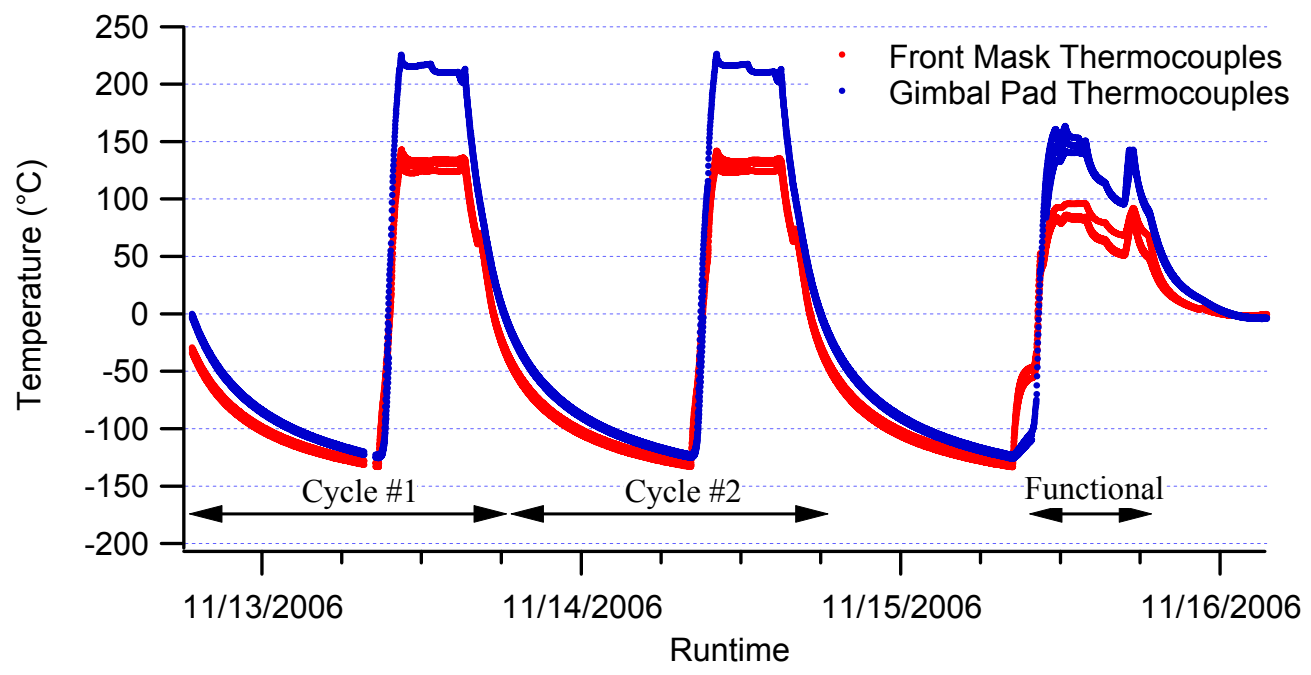

Fig. 12. - Thermal vacuum testing temperature profile.

\section{G. Thruster Functional Testing}

Thruster functional testing was performed in the same manner for all functional tests during the environmental test program. Despite the difficulties in starting the neutralizer heater at the end of the thermal-vacuum testing, the engine performed nominally during all of the final performance testing. Non-controlled and derived engine performance parameters for the lower-power operating conditions are compared for all functional tests in Table 6 . It can be seen that there were no major differences in performance throughout the environmental test program at these power levels. Minor differences of up to a few percent were observed in the non-controlled operating parameters. Discharge chamber parameters and accelerator grid current were likely influenced by the tank pressure differences of up to 10 percent between tests, caused by graphite panel gas absorption/desorption during the frequent vacuum cycles and rapid tests. Changes in discharge chamber neutral density caused by ingested flow affect discharge performance through the primary electron loss rate and electron temperature, for example (Ref. 19). Neutral density near the accelerator grid is also a significant factor in charge-exchange ion production and accelerator grid current. 
Table 6.-Engine Performance for the Lower-Power Functional Test Points

\begin{tabular}{|l|c|c|c|c|c|c|}
\hline & \multicolumn{3}{|c|}{1.2 A, 679 V } & \multicolumn{3}{c|}{2.0 A, 1179 V } \\
\hline & Pre-Vibe & $\begin{array}{c}\text { Post- } \\
\text { Vibe }\end{array}$ & $\begin{array}{c}\text { Post- } \\
\text { Thermal }\end{array}$ & Pre-Vibe & Post-Vibe & $\begin{array}{c}\text { Post- } \\
\text { Thermal }\end{array}$ \\
\hline Discharge Current (A) & 10.2 & 10.4 & 9.9 & 13.9 & 13.9 & 13.7 \\
Discharge Voltage (V) & 26.6 & 25.8 & 26.2 & 24.5 & 23.7 & 23.9 \\
Cathode Keeper Voltage (V) & 4.0 & 3.7 & 4.0 & 3.9 & 3.9 & 3.9 \\
Accelerator Grid Current (mA) & 3.7 & 3.8 & 3.9 & 7.2 & 7.5 & 7.8 \\
Neutralizer Keeper Voltage (V) & 13.5 & 14.3 & 13.9 & 13.3 & 13.8 & 13.5 \\
Power (W) & 1130 & 1130 & 1120 & 2760 & 2740 & 2740 \\
Tank Pressure (Torr Xe) & $1.9 \mathrm{E}-06$ & $1.7 \mathrm{E}-06$ & $2.1 \mathrm{E}-06$ & $3.0 \mathrm{E}-06$ & $2.7 \mathrm{E}-06$ & $3.2 \mathrm{E}-06$ \\
Thrust (mN) & 49.2 & 49.2 & 49.1 & 109 & 109 & 108 \\
Specific Impulse (sec) & 2440 & 2440 & 2440 & 3500 & 3480 & 3480 \\
Total Efficiency & 0.521 & 0.522 & 0.526 & 0.677 & 0.676 & 0.676 \\
Beam Ion Energy Cost (eV/ion) & 227 & 224 & 216 & 169 & 165 & 163 \\
\hline
\end{tabular}

Slight variations in the derived parameters, such as the beam ion energy cost, reflect the differences in measured parameters. The largest effect on the efficiency at the lowest power was the change in discharge power.

Engine performance for the $3.52 \mathrm{~A}, 1179 \mathrm{~V}$ operating condition is shown in Table 7, which includes performance from the two thermal cycles where the engine was operating at elevated temperatures. Again, no major differences in performance were observed with the exception of the accelerator grid current which is almost certainly due to tank pressure variations (it will be shown later that optics performance was essentially unchanged during the testing). Performance data for the full-power operating condition are summarized in Table 8. As for the mid-power cases shown in Table 7, performance was largely the same with the exception of variations in the accelerator grid current due to tank pressure. Note that outgassing from the thruster and/or thermal shroud may have also contributed to the higher measure tank pressures during the thermal cycle testing at elevated temperatures.

Table 7.-Engine Performance for the 3.52 A, 1179 V Operating Condition

\begin{tabular}{|l|c|c|c|c|c|}
\hline & Pre-Vibe & $\begin{array}{c}\text { Post- } \\
\text { Vibe }\end{array}$ & $\begin{array}{c}\text { Thermal } \\
\text { Cycle \#1 }\end{array}$ & $\begin{array}{c}\text { Thermal } \\
\text { Cycle \#2 }\end{array}$ & $\begin{array}{c}\text { Post- } \\
\text { Thermal }\end{array}$ \\
\hline Discharge Current (A) & 19.5 & 19.3 & 19.2 & 19.3 & 19.5 \\
Discharge Voltage (V) & 23.9 & 24.1 & 23.4 & 23.4 & 23.5 \\
Cathode Keeper Voltage (V) & 5.5 & 5.5 & 5.5 & 5.4 & 5.3 \\
Accelerator Grid Current (mA) & 20.7 & 18.4 & 29.5 & 26.2 & 20.7 \\
Neutralizer Keeper Voltage (V) & 12.0 & 11.9 & 12.2 & 12.0 & 12.0 \\
Power (W) & 4660 & 4660 & 4670 & 4660 & 4660 \\
Tank Pressure (Torr Xe) & $5.1 \mathrm{E}-06$ & $4.9 \mathrm{E}-06$ & $6.3 \mathrm{E}-06$ & $5.9 \mathrm{E}-06$ & $5.6 \mathrm{E}-06$ \\
Thrust (mN) & 191 & 191 & 191 & 191 & 191 \\
Specific Impulse (sec) & 3380 & 3380 & 3380 & 3380 & 3380 \\
Total Efficiency & 0.679 & 0.679 & 0.679 & 0.680 & 0.679 \\
Beam Ion Energy Cost (eV/ion) & 132 & 132 & 128 & 128 & 130 \\
\hline
\end{tabular}

Ion optics performance measurements are compared for all functional testing in Table 9. Note that during the thermal vacuum testing perveance measurements were not made, nor were electron backstreaming (EBS) measurements made at the two lower power conditions. There were no measurable changes observed in optics performance as a result of the vibration testing; all the differences were within measurement error. Comparison of EBS data with the $3.52 \mathrm{~A}, 1179 \mathrm{~V}$ operating condition in the pre-vibe test was inconclusive because of the difficulty in getting a good measurement with the frequent engine recycling during the measurement.

Differences between post-vibe and post-thermal perveance limits were in general larger than for the pre- and post-vibe measurements. This difference is not significantly larger than the measurement error, and thus is not necessarily an indication of a hardware change related to the thermal-vacuum test. There was no notable difference in the EBS data for the post-vibe, thermal-vacuum, and post-thermal tests. 
Table 8. - Engine Performance for the 3.52 A, $1800 \mathrm{~V}$ Operating Condition

\begin{tabular}{|l|c|c|c|c|c|}
\hline & Pre-Vibe & $\begin{array}{c}\text { Post- } \\
\text { Vibe }\end{array}$ & $\begin{array}{c}\text { Thermal } \\
\text { Cycle \#1 }\end{array}$ & $\begin{array}{c}\text { Thermal } \\
\text { Cycle \#2 }\end{array}$ & $\begin{array}{c}\text { Post- } \\
\text { Thermal }\end{array}$ \\
\hline Discharge Current (A) & 18.1 & 18.0 & 18.0 & 18.1 & 17.8 \\
Discharge Voltage (V) & 23.2 & 23.4 & 23.0 & 22.9 & 23.5 \\
Cathode Keeper Voltage (V) & 5.4 & 5.4 & 5.4 & 5.4 & 5.5 \\
Accelerator Grid Current (mA) & 20.8 & 18.2 & 25.8 & 21.7 & 19.8 \\
Neutralizer Keeper Voltage (V) & 12.0 & 12.0 & 12.2 & 12.0 & 12.1 \\
Power (W) & 6860 & 6840 & 6840 & 6830 & 6820 \\
Tank Pressure (Torr Xe) & $5.5 \mathrm{E}-06$ & $5.2 \mathrm{E}-06$ & $6.2 \mathrm{E}-06$ & $5.9 \mathrm{E}-06$ & $5.5 \mathrm{E}-06$ \\
Thrust (mN) & 238 & 237 & 237 & 237 & 236 \\
Specific Impulse (sec) & 4190 & 4190 & 4170 & 4170 & 4180 \\
Total Efficiency & 0.712 & 0.712 & 0.708 & 0.709 & 0.710 \\
Beam Ion Energy Cost (eV/ion) & 119 & 120 & 117 & 118 & 119 \\
\hline
\end{tabular}

Table 9.--Ion Optics Functional Test Data

\begin{tabular}{|c|l|c|c|c|c|c|}
\hline & $\begin{array}{c}\text { Operating } \\
\text { Condition }\end{array}$ & Pre-Vibe & $\begin{array}{c}\text { Post- } \\
\text { Vibe }\end{array}$ & $\begin{array}{c}\text { Thermal } \\
\text { Cycle \#1 }\end{array}$ & $\begin{array}{c}\text { Thermal } \\
\text { Cycle \#2 }\end{array}$ & $\begin{array}{c}\text { Post- } \\
\text { Thermal }\end{array}$ \\
\hline & $1.2 \mathrm{~A}, 679 \mathrm{~V}$ & 578 & 584 & $\times$ & $\times$ & 568 \\
Perveance & $2.0 \mathrm{~A}, 1179 \mathrm{~V}$ & 693 & 687 & $\times$ & $\times$ & 695 \\
Limit (V) & $3.52 \mathrm{~A}, 1179 \mathrm{~V}$ & 861 & 863 & $\times$ & $\times$ & 851 \\
& $3.52 \mathrm{~A}, 1800 \mathrm{~V}$ & 855 & 859 & $\times$ & $\times$ & 844 \\
\hline Electron- & $1.2 \mathrm{~A}, 679 \mathrm{~V}$ & -49 & -49 & $\times$ & $\times$ & -47 \\
Backstreaming & $2.0 \mathrm{~A}, 1179 \mathrm{~V}$ & -99 & -97 & $\times$ & $\times$ & -98 \\
Limit (V) & $3.52 \mathrm{~A}, 1179 \mathrm{~V}$ & $-137^{*}$ & -117 & -119 & -119 & -118 \\
& $3.52 \mathrm{~A}, 1800 \mathrm{~V}$ & -161 & -165 & -161 & -166 & -164 \\
\hline \hline
\end{tabular}

*NOTE: there was significant engine recycling during this measurement that likely affected the result.

A significant amount of beam current density data were acquired during the pre- and postvibration functional testing. Unfortunately, the mechanical stage used to articulate the Faraday probes failed at the beginning of the thermal vacuum testing and could not be used to collect data at the standard test conditions for the remainder of the testing. A subset of the available data is presented here to compare the functional results before and after vibration testing. Shown in Fig. 13 are data acquired during two functional test operating conditions at the standard $45 \mathrm{~mm}$ distance from the ion optics face. The slight differences between data collected before and after the vibration test are typical of those seen at the other operating conditions and distances. To investigate if a significant shift had occurred as a result of vibration testing, the probe data were examined in greater detail and it was determined that the differences observed were not significantly larger than the errors associated with collecting and analyzing the data. This conclusion is consistent with the similar results obtained for ion optics measurements.

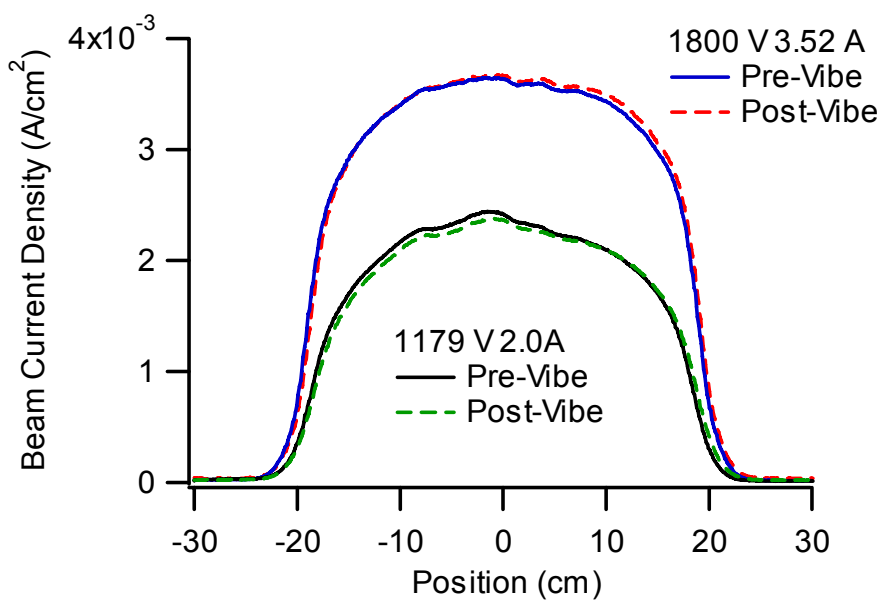

Fig. 13.-Pre- and post-vibration beam current density measured $45 \mathrm{~mm}$ from accelerator grid. 
Results of the neutralizer characterization for the post-vibe and post-thermal functional tests are shown in Fig. 14. Results for the pre-vibration testing are not shown because interpretation of the data was difficult due to experimental complications. The spot-to-plume-mode transition, as defined by the presence of $5 \mathrm{~V}$ peak-to-peak fluctuations in the neutralizer keeper voltage, was at $3.3 \mathrm{sccm}$ for both tests in Fig. 14. This value is the same as that measured in the PM1 performance evaluation conducted prior to the thermal development test (Ref. 11).

Cathode ignition times were recorded for all engine starts during the environmental test program, and a subset of those results are summarized in Table 10. Cathode ignition time is defined as the time elapsed from the beginning of the ignition procedure until a plasma discharge is

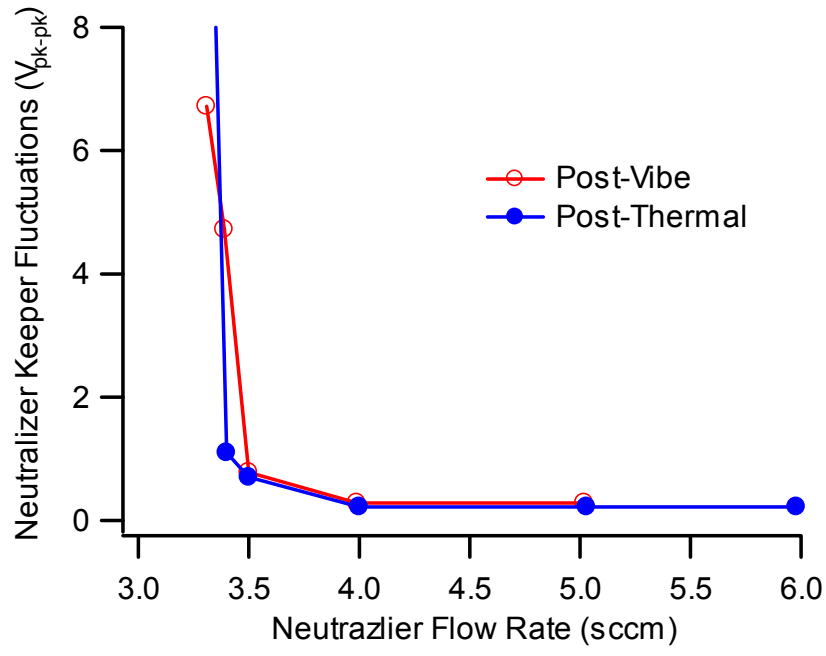

Fig. 14. - Neutralizer characterization test results. produced. Starts are labeled ambient if the engine and cathode were a ambient chamber temperatures prior to the start attempt; cold starts were those performed after cooling of the engine with the thermal shroud at liquid nitrogen temperatures; warm starts were those performed within approximately one hour after previous cathode operation; and hot restarts were those performed within minutes after previous cathode operation. Neutralizer ignition times showed a slight dependence on cathode temperature during the environmental testing. The average ignition time for a warm/hot neutralizer was 3.5 minutes, and for an ambient/cold neutralizer was 4.3 minutes. In contrast, the discharge cathode ignition time showed a strong dependence on temperature. The average ignition time for warm/hot cathodes was a nominal 3.6 minutes, whereas the ambient/cold start times averaged 6.5 minutes. There did not appear to be any effect on ignition time due to the vibration or thermal-vacuum tests from the limited data available. Discharge cathode ignition time findings will require further analysis with regard to life validation and system-level impact before it is determined if a hardware change is necessary.

Table 10.-Cathode Ignition Times

\begin{tabular}{|c|c|c|c|}
\hline Test & $\begin{array}{c}\text { Discharge } \\
\text { Cathode } \\
\text { Ignition } \\
\text { Time (min) }\end{array}$ & $\begin{array}{c}\text { Neutralizer } \\
\text { Ignition } \\
\text { Time (min) }\end{array}$ & Notes \\
\hline Post-Vibe & 8.7 & 4.0 & Ambient start \\
Performance & 6.4 & 4.2 & Ambient start \\
& 6.9 & 4.2 & Ambient start \\
\hline & 6.1 & 4.2 & Cold start \\
Pre-Thermal- & 5.9 & 4.4 & Cold start \\
Vacuum & 5.3 & 3.8 & Warm start \\
Operation & 3.7 & 3.5 & Ambient start \\
& 6.3 & 4.3 & Cold start \\
& 7.2 & 4.6 & Hot Restart \\
\hline Thermal & 3.5 & 3.5 & Cold start \\
Cycle \#1 & 6.1 & 4.6 & Hot Restart \\
\hline Thermal & 3.5 & 3.5 & Cold start \\
Cycle \#2 & 5.6 & $\times$ & Heater failed at first start \\
\hline & & 3.5 & attempt, later started with \\
Post-Thermal & $\times$ & 3 enmental heating \\
Performance & $\times$ &
\end{tabular}




\section{H. Final Inspection}

After completion of the post-thermal functional testing the engine was removed from the vacuum facility and given a complete physical and electrical inspection. The discharge and neutralizer cathode impedances were nominal and there were no other significant findings as a part of the electrical inspection. Likewise, there were no significant additional findings as a part of the physical inspection. It was noted, however, that the debris observed within in the discharge chamber (see Fig. 11) no longer had the same localized concentration, likely a result of handling the thruster and placing it in a horizontal orientation for testing. The neutralizer housing cover was removed for visual inspection which revealed no immediate cause for the heater failure during thermal-vacuum testing.

\section{Conclusion}

Environmental testing of the NEXT PM1 ion engine and gimbal assembly was completed according to NEXT project requirements. Functional tests of the engine and the gimbal were performed prior to and after both vibration and thermal vacuum testing.

Random vibration testing was performed at levels of $10.0 \mathrm{G}_{\mathrm{rms}}$ in three axes at two minutes per axis for the PM1 thruster and breadboard gimbal assembly. Testing in each axis was successfully completed, although with several issues uncovered. The major issues encountered during the vibration test sequence were discharge and neutralizer heater impedance variations, particulate contamination generation, and fastener backouts on both the thruster and gimbal.

Significant particulate contamination inside the engine was observed and was traced to fragmentation of the potting cement on the cathode heater terminations, nutplate wear, residue remaining inside the engine from manufacturing processes, and fraying fiberglass wire insulation. In many instances the amount of contamination generated was in excess of typical spacecraft cleanliness requirements.

In addition, pre- and post-test sine surveys showed some significant differences indicating some changes to the test hardware. The largest of those was identified as a change in the load path near gimbal leg $\mathrm{C}$, likely in the breadboard gimbal hardware but possibly occurring within the thruster immediately next to the gimbal pad. Inspection of the test hardware yielded no evidence of a cause for the sine survey shift, hence the most likely cause was determined to be a slight hardware settling at the leg $\mathrm{C}$ thruster gimbal bracket. Gimbal functional tests performed prior to and after the vibration test were successful with nearly identical performance in each instance.

Thermal vacuum testing began with a deep cold soak to temperatures below $-160{ }^{\circ} \mathrm{C}$ on the PM1 gimbal pads and front mask. Following a non-operational thermal cycle, the thruster was successfully subjected to two of three planned thermal cycles of temperature range $-120{ }^{\circ} \mathrm{C}$ to $203{ }^{\circ} \mathrm{C}$. On the third attempt to start the thruster the neutralizer heater failed to pass current, most likely related to the impedance anomalies observed in vibration testing. Environmental heating was applied to the neutralizer and heater operation was recovered, allowing engine operation. Post-thermal-vacuum functional testing was then successfully performed.

Thruster performance was nominal throughout the test program. There were noticeable changes in some thruster operational parameters, likely related to modest differences in tank pressure between different test phases, but no indication of a major change in thruster performance or operation resulting from exposure to the vibration and thermal environments. Similarly, there was no major change in ion optics performance or beam current density data. Although neutralizer cathode ignition times were consistent and showed little dependence on temperature, the discharge cathode ignition times showed a strong dependence on temperature.

In general, the NEXT PM1 engine and the breadboard gimbal were found to be well-designed against environmental requirements based on the results reported herein, although there were issues uncovered during the testing. The minor findings (e.g. loose fasteners) should be easily resolvable. With modest redesign efforts targeted at the cathode heaters, and with materials and processes solutions to the contamination findings, these issues can also be corrected. Discharge cathode ignition time findings will require further analysis with regard to life validation and system-level impact before it is determined if a hardware change is necessary. After resolution of the findings from this test program the hardware environmental qualification program can proceed with confidence.

\section{References}

1. M.J. Patterson and S.W. Benson, "NEXT Ion Propulsion System Development Status and Performance," AIAA Paper 2007-5199, to be presented at the 43rd Joint Propulsion Conference, Cincinnati, OH, July 2007.

2. D. Oh, S. Benson, K. Witzberger, and M. Cupples, "Deep Space Mission Applications for NEXT: NASA's Evolutionary Xenon Thruster," AIAA 2004-3806, 40th Joint Propulsion Conference, Fort Lauderdale, FL, July 2004. 
3. J.R. Brophy, "NASA's Deep Space 1 Ion Engine," Review of Scientific Instruments, Vol. 73, No. 2, Feb. 2002, pp. 1071-1078.

4. J.R. Brophy, et. al, "Development and Testing of the Dawn Ion Propulsion System," AIAA-2006-4319, 42nd Joint Propulsion Conference, Sacramento, CA, July 2006.

5. G.C. Soulas, M.T. Domonkos, and M.J. Patterson, "Performance Evaluation of the NEXT Ion Engine," AIAA2003-5278, 39th Joint Propulsion Conference, Huntsville, AL, July 2003.

6. G.C. Soulas, H. Kamhawi, M.J. Patterson, M.A. Britton, and M.M. Frandina, "NEXT Ion Engine 2000 Hour Wear Test Results," AIAA-2004-3791, 40th Joint Propulsion Conference, Fort Lauderdale, FL, July 2004.

7. M.J. Patterson, L.R. Piñero, R. Aadland, and D. Komm, "NEXT Ion Propulsion System: Single-String Integration Test Results," JANNAF Conference, May 2004.

8. D.A. Herman, G.C. Soulas, and M.J. Patterson, "Status of the NEXT Ion Thruster Long Duration Test," AIAA2007-5272, to be presented at the 43rd Joint Propulsion Conference, Cincinnati, OH, July 2007.

9. M.J. Patterson, J. Foster, H. McEwen, E. Pencil, J. Van Noord, and D. Herman, "NEXT Multi-Thruster Array Test-Engineering Demonstration," AIAA-2006-5180, 42nd Joint Propulsion Conference, Sacramento, CA, July 2006.

10. W.A. Hoskins, F.C. Wilson, J. Polaha, L. Talerico, M.J. Patterson, G.C. Soulas, and J. Sovey, "Development of a Prototype Model Ion Thruster for the NEXT System," AIAA-2004-4111, 40th Joint Propulsion Conference, Fort Lauderdale, FL, July 2004.

11. D.A. Herman, G.C. Soulas, and M.J. Patterson, "Performance Evaluation of the Prototype-Model NEXT Ion Thruster," AIAA-2007-5212, to be presented at the 43rd Joint Propulsion Conference, Cincinnati, OH, July 2007.

12. J.R. Anderson, J.S. Snyder, J. Van Noord, and G.C. Soulas, "Thermal Development Test of the NEXT PM1 Ion Engine," AIAA-2007-5217, to be presented at the 43rd Joint Propulsion Conference, Cincinnati, OH, July 2007.

13. J.L. Van Noord, "NEXT Ion Thruster Thermal Model," AIAA-2007-5218, to be presented at the 43rd Joint Propulsion Conference, Cincinnati, OH, July 2007.

14. D.A. Vaughan, "Gimbal Development for the NEXT Ion Propulsion System," AIAA-2005-3865, 41st Joint Propulsion Conference, Tucson, AZ, July 2005.

15. J.S. Snyder, M.R. O'Connell, J.P. Fernandez, G. Wang, R.S. McNabb, Jr., and D. Crumb, "Vibration Test of a Breadboard Gimbal for the NEXT Ion Engine, AIAA-2006-4665, 42 ${ }^{\text {nd }}$ Joint Propulsion Conference, Sacramento, CA, July 2006.

16. NASA-HDBK-7004B, "Force Limited Vibration Testing," NASA Technical Handbook, January 31, 2003.

17. S.W. Benson, M.J. Patterson, D.A. Vaughan, A.C. Wilson, and B.R. Wong, "NASA's Evolutionary Xenon Thruster (NEXT) Phase 2 Development Status," AIAA-2005-4070, 41st Joint Propulsion Conference, Tucson, AZ, July 2005.

18. J.A. Christensen, et al., "Design and Fabrication of a Flight Model $2.3 \mathrm{~kW}$ Ion Thruster for the Deep Space 1 Mission,” AIAA-98-3327, 34th Joint Propulsion Conference, Cleveland, OH, July 1998.

19. D.M. Goebel, R.E. Wirz, and I. Katz, "Analytical Ion Thruster Discharge Performance Model, AIAA-20064486, 42nd Joint Propulsion Conference, Sacramento, CA, July 2006. 


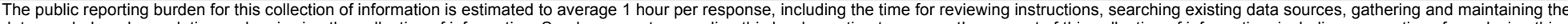

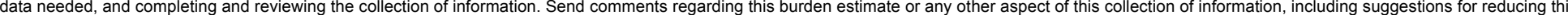

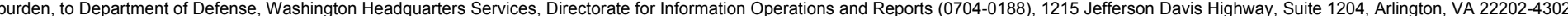

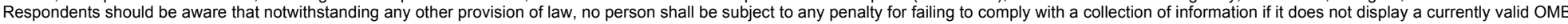
control number.

PLEASE DO NOT RETURN YOUR FORM TO THE ABOVE ADDRESS

\section{REPORT DATE (DD-MM-YYYY) \\ 2. REPORT TYPE \\ 3. DATES COVERED (From - To)}

01-01-2008

Technical Memorandum

\section{TITLE AND SUBTITLE}

Environmental Testing of the NEXT PM1 Ion Engine

\section{5a. CONTRACT NUMBER}

5b. GRANT NUMBER

5c. PROGRAM ELEMENT NUMBER

\section{AUTHOR(S}

Snyder, John, Steven; Anderson, John, R.; Van Noord, Jonathan, L.; Soulas, George, C.

\section{5d. PROJECT NUMBER}

5e. TASK NUMBER

5f. WORK UNIT NUMBER

WBS 346620.04.05.03.11

8. PERFORMING ORGANIZATION

REPORT NUMBER

E-16186

\section{PERFORMING ORGANIZATION NAME(S) AND ADD
National Aeronautics and Space Administration}

John H. Glenn Research Center at Lewis Field

Cleveland, Ohio 44135-3191

\section{SPONSORING/MONITORING AGENCY NAME(S) AND ADDRESS(ES)}

National Aeronautics and Space Administration

Washington, DC 20546-0001

\section{SPONSORING/MONITORS ACRONYM(S) \\ NASA \\ 11. SPONSORING/MONITORING REPORT NUMBER \\ NASA/TM-2008-215014}

\section{DISTRIBUTION/AVAILABILITY STATEMENT}

Unclassified-Unlimited

Subject Category: 20

Available electronically at http://gltrs.grc.nasa.gov

This publication is available from the NASA Center for AeroSpace Information, 301-621-0390

\section{SUPPLEMENTARY NOTES}

\section{ABSTRACT}

The NEXT propulsion system is an advanced ion propulsion system presently under development that is oriented towards robotic exploration of the solar system using solar electric power. The Prototype Model engine PM1 was subjected to qualification-level environmental testing to demonstrate compatibility with environments representative of anticipated mission requirements. Random vibration testing, conducted with the thruster mated to the breadboard gimbal, was executed at $10.0 \mathrm{G}_{\mathrm{rms}}$ for 2 minutes in each of three axes. Thermalvacuum testing included a deep cold soak of the engine to temperatures of $-168{ }^{\circ} \mathrm{C}$ and thermal cycling from -120 to $203{ }^{\circ} \mathrm{C}$. Although the testing was largely successful, several issues were identified including the fragmentation of potting cement on the discharge and neutralizer cathode heater terminations during vibration which led to abbreviated thermal testing, and generation of particulate contamination from manufacturing processes and engine materials. Thruster performance was nominal throughout the test program, with minor variations in some engine operating parameters likely caused by facility effects. In general, the NEXT PM1 engine and the breadboard gimbal were found to be well-designed against environmental requirements based on the results reported herein. After resolution of the findings from this test program the hardware environmental qualification program can proceed with confidence.

\section{SUBJECT TERMS}

Ion thruster; Ion engine; Ion propulsion

\begin{tabular}{|l|l|l|l|}
\hline \multicolumn{2}{|l|}{ 16. SECURITY CLASSIFICATION OF: } & $\begin{array}{l}\text { 17. LIMITATION OF } \\
\text { ABSTRACT }\end{array}$ \\
\begin{tabular}{|l|l|} 
a. REPORT & b. ABSTRACT
\end{tabular} & $\begin{array}{l}\text { c. THIS } \\
\text { PAGE } \\
\text { U }\end{array}$ & UU \\
\hline
\end{tabular}

18. NUMBER
OF
PAGES
24

\section{9a. NAME OF RESPONSIBLE PERSON STI Help Desk (email:help@sti.nasa.gov) 19b. TELEPHONE NUMBER (include area code) $301-621-0390$}



